OPEN ACCESS

Edited by: Jason M. R. Gill,

University of Glasgow, United Kingdom

Reviewed by: Jim Winger,

Loyola University Chicago,

United States

Georgia Torres,

University of the Witwatersrand,

South Africa

*Correspondence:

Stefan I. Madansingh stefan@zibrio.com

Specialty section:

This article was submitted to Physical Activity in the Prevention and

Management of Disease,

a section of the journal

Frontiers in Sports and Active Living

Received: 18 March 2021

Accepted: 31 August 2021

Published: 24 September 2021

Citation:

Forth KE, Layne CS and Madansingh SI (2021) Self-Monitoring of Balance Performance Can Reduce the Rate of Falls Among Older Adults.

Front. Sports Act. Living 3:680269.

doi: 10.3389/fspor.2021.680269

\section{Self-Monitoring of Balance Performance Can Reduce the Rate of Falls Among Older Adults}

\author{
Katharine E. Forth ${ }^{1}$, Charles S. Layne ${ }^{2,3,4}$ and Stefan I. Madansingh ${ }^{1 *}$ \\ 'Zibrio Inc., Houston, TX, United States, ${ }^{2}$ Department of Health and Human Performance, University of Houston, Houston, \\ TX, United States, ${ }^{3}$ Center for Neuromotor and Biomechanics Research, University of Houston, Houston, TX, United States, \\ ${ }^{4}$ Center for Neuro-Engineering and Cognitive Science, University of Houston, Houston, TX, United States
}

Background: 29\% of older adults fall annually, resulting in the leading cause of accidental death. Fall prevention programs typically include exercise training and self-monitoring of physical activity has a positive effect on the self-efficacy and self-regulation of exercise behaviors. We assessed if self-monitoring of fall risk, without an intervention, impacts fall rates.

Methods: Fifty-three older adults had open access to a balance measuring platform which allowed them to self-monitor their postural stability and fall risk using a simple 1-min standing balance test. 12-month retrospective fall history was collected and a monthly/bimonthly fall log captured prospective falls. Participants had access to self-monitoring for up to 2.2 years. Fall history and fall incidence rate ratios and their confidence intervals were compared between the periods of time with and without access to self-monitoring.

Results: A 54\% reduction in the number of people who fell and a 74\% reduction in the number of falls was observed when participants were able to self-monitor their postural stability and fall risk, after normalizing for participation length. Further, $42.9 \%$ of individuals identified as having high fall risk at baseline shifted to a lower risk category at a median 34 days and voluntarily measured themselves for a longer period of time.

Discussion: We attribute this reduction in falls to changes in health behaviors achieved through empowerment from improved self-efficacy and self-regulation. Providing older adults with the ability to self-monitor their postural stability and intuit their risk of falling appears to have modified their health behaviors to successfully reduce fall rates.

Keywords: balance, fall risk analysis in older people, postural stability (postural control), older adult, balance health

\section{INTRODUCTION}

Each year, $28.7 \%$ of older adults fall in the US resulting in 300,000 hip fractures, over $\$ 50$ billion dollars in medical costs (Florence et al., 2018), and is the leading cause of accidental death in this population (Gillespie et al., 2012). Many risk factors, including both extrinsic and intrinsic factors, have been identified as related to falling in older adults, including: cognitive impairment, use of sedatives, balance and gait abnormalities, disabilities of the lower limbs, foot problems (Tinetti et al., 1988), vison impairment (Lord and Dayhew, 2001), fall history (Ganz et al., 2007), and fear of falling 
(Young and Mark Williams, 2015). Environmental hazards and the accidents they cause represent the greatest contributors to falls and are cited as the cause of $30-50 \%$ of all falls (Rubenstein, 2006). Rubenstein (2006) explains, however, that intrinsic weaknesses stemming from age and disease or loss of function provide an increased susceptibility to hazards, making older adults more vulnerable to environmental challenges to their postural stability (Rubenstein, 2006).

While some risk factors are permanent, many risk factors can be modulated and these are targeted in fall prevention programs. In fact, a number of lifestyle health behaviors, particularly exercise, are known to influence and reduce the risk of falling (Shumway-Cook et al., 1997; Taggart, 2002; Grabiner et al., 2012; Halvarsson et al., 2015; Shier et al., 2016; Sherrington et al., 2017). Yet, less than half of the older adult population exercise sufficiently for general health benefits, and that number is further reduced for those aged 75 and older (Schoenborn et al., 2013). This deficiency of physical activity in older adults presents a clear opportunity for reducing the likelihood of falling. In fact, many fall prevention interventions include a form of exercise as a major component of their program. As a result, interventions focused on changing exercise health behaviors may also provide an opportunity for changing health behaviors beneficial to fall preventing a fall, such as increasing one's awareness of balance health and fall risk.

Current literature identifies self-efficacy and self-regulation (Bandura, 1991; Lee et al., 2007, 2008) as key components for creating positive health behavior changes in exercise intervention programs. Lee et al. (2008) identify knowledge of "performance accomplishments" and one's "physiological state" as two of the four information sources required for older adults to achieve self-efficacy and overcome psychological barriers to exercise. Selfmonitoring that provides feedback and information relating to a particular behavior, has been found to empower individuals in exercise initiation and adherence for a positive effect on exercise health behaviors (Michie et al., 2009). Currently, wearable and connected technologies have made self-monitoring possible for a variety of lifestyle and health metrics. The self-monitoring offered by pedometers, for example, have created positive change in health behaviors and have increased physical activity (Wang et al., 2016; Maher et al., 2017; Sullivan and Lachman, 2017).

Given the overlap between fall prevention and exercise interventions, we hypothesize that providing knowledge of balance performance through unconstrained and longitudinal self-monitoring of postural stability as an indicator of fall risk will serve as a behavioral intervention to reduce the observed rate of falls in older adults.

Presently, there is no at-home method for self-monitoring fall risk and there is limited capacity for fall risk testing within the clinical setting. In this study, we provided residents at a senior living facility and older adults who regularly visit a community center for seniors access to easy-to-use technology which measures postural stability as an indicator of fall risk and tracked them longitudinally to determine if self-monitoring influenced their rate of falls.

\section{METHODS}

Fifty-three older adults (age $80.4 \pm 10.4$ years) (mean \pm SD) were recruited from two locations: an independent Senior Living Facility (SLF), $n=30$ (25 female), and a Senior Community Center (SCC), $n=23$ (18 female). Individuals were unable to participate if they could not stand for $60 \mathrm{~s}$ unassisted or if they self-reported a history of neurodegenerative, vestibular or balance related disease, or had experienced a significant musculoskeletal injury within the last 6 months which limited their ability to stand unassisted. The experimental protocol was approved by the University of Houston Institutional Review Board (IRB), and informed consent was obtained prior to participation.

Each participant performed an eyes-open test of quiet stance on a laboratory-grade force plate (AMTI, Watertown, MA, USA) for $60 \mathrm{~s}$. Participants were instructed to stand comfortably, with their arms to their sides and their eyes forward. Participants were also instructed to stand as still as they possibly could, without moving or talking. Center of pressure (COP) was captured at $100 \mathrm{~Hz}$ on the force-plate. Custom software (Labview 2011, National Instruments, TX, USA) was used to calculate a score (from 1 to 10) from the COP data, reflecting an estimate of the participant's postural stability and was referred to as a "balance score." Briefly, this custom software collected the COP data then performed linear quantifications of postural sway, including: path length, velocity, acceleration and jerk, in both anterior-posterior and medial-lateral directions, as well as nonlinear measures of postural stability characterized using a Hidden Markov Model (Rasku et al., 2008; Joutsijoki et al., 2019) were utilized as factors (Forth and Lieberman Aiden, 2019) to calculate the balance score. A score of 1 suggested the lowest stability and 10 suggested the highest stability. The numeric score was displayed on a nearby computer display after the test with an associated color denoting fall risk category. Scores ranging 13 indicated high fall risk coinciding with a "red" risk group; scores ranging 4-6 indicated moderate fall risk, coinciding with a "yellow" risk group and scores ranging 7-10 indicated low fall risk coinciding with a "green" risk group (Forth et al., 2020). This "balance score" was immediately made available to the participant upon completion of the test and placed within the context of visual imagery depicting less independence and increased frailty for scores in the "red" risk group and increased independence and low frailty for scores in the "green" risk group. Participants were assured that no categorization was permanent and encouraged to test themselves regularly to track their progress, see Figure 1 for a representative sample.

The testing equipment that provided a postural stability ("balance") score was available to the SLF for 2.2 years and could be operated at their discretion during this time. The number of tests performed by each participant was recorded. The SCC participants were given three opportunities to test themselves across 6 months, resulting in an approximately bimonthly testing schedule. The duration of prospective monitoring was calculated as the difference between the first test date and the last test date for each individual, representing their participation in personyears (Young, 2005). 


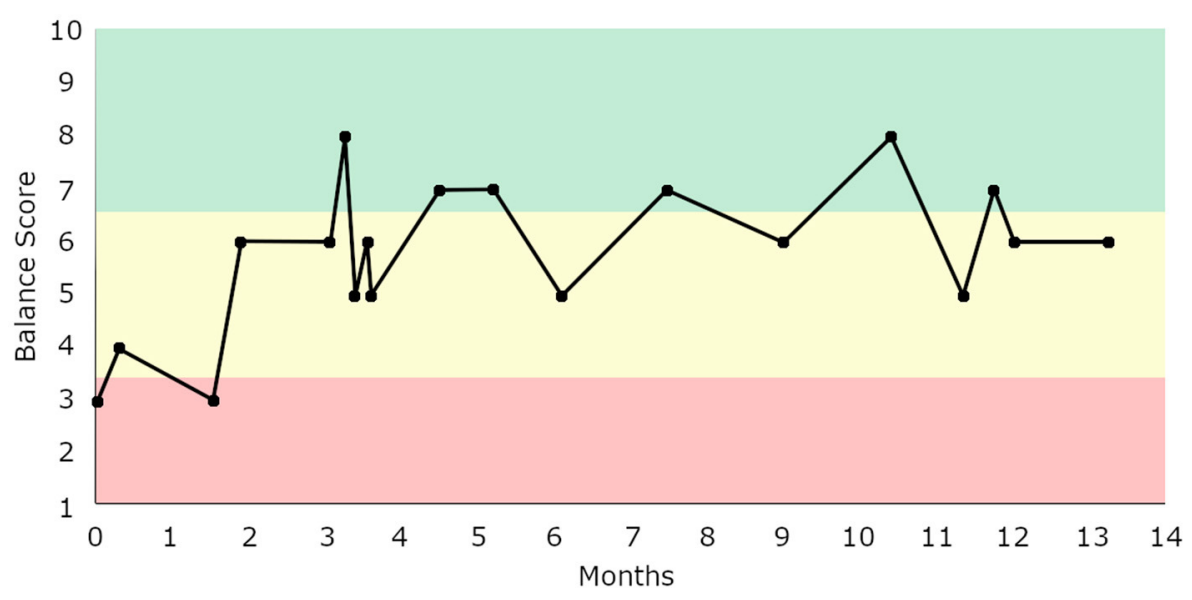

FIGURE 1 | Balance score tracking for a representative older adult who self-selected to assess their postural stability 18 times over the span of 14 months. This individual transitioned from initially scoring in the "high risk" zone (1-3) to comfortably staying within the "moderate risk" zone (4-6), occasionally entering the "low risk" zone.

Six and 12 month fall history was recorded at the first test and a fall log was obtained via monthly (SLF) or bimonthly (SCC) follow-up phone interview for the duration of study participation (Hannan et al., 2010). A fall event was counted if the participant confirmed that they had "unintentionally reached the ground or a lower level" (Tinetti et al., 1988) during follow-up interviews. Falls resulting from episodes of syncope caused by orthostatic intolerance, or other factors, were not considered balance related falls and were not counted in this study.

To quantify the impact of self-monitoring and knowledge of balance performance upon rates of falls, incidence rate ratios (IRR) and their 95\% confidence intervals were calculated to compare: the rate of past falls $[I R R($ falls $)]$ and the observed rate of prospective (future) falls, as well as the number of past fallers with the number of participants who experienced a fall during the prospective portion of the study [IRR(fallers)]. A percentage reduction was also calculated comparing the number of past fall events with the number of observed fall events occurring after access to self-monitoring of postural stability ("balance score") was made available. Incidence and percentage reductions were additionally calculated for all individuals who completed at least 6 and 12 months of self-monitoring. These estimates provided the ability to monitor trends in the calculated IRR for those participants who had monitored time equaling the retrospective period.

The equations for calculating the total person-years for the retrospective and prospective fall data are below:

$$
\begin{aligned}
\sum \text { person }_{\text {years }} \text { retro } & =n \\
\sum \text { person|years } & =\sum_{i=1}^{n} \text { duration of prospective monitoring } \\
& =\sum_{i=1}^{n} \frac{k_{\text {daysEnrolled }}^{365}}{365}
\end{aligned}
$$

The calculations for the fall rate incidence for retrospective $\left(\mathrm{IR}_{\text {retro }}\right)$ and fall rate incidence for the prospective $\left(\mathrm{IR}_{\text {pros }}\right)$ are listed before for both fall incidence and number of fallers.

$$
\begin{aligned}
& \# \text { fall }_{\text {retro }}=\text { number of retrospective fall events } \\
& \# \text { falls } s_{\text {pros }}=\text { number of prospective fall events }
\end{aligned}
$$

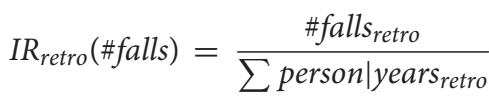

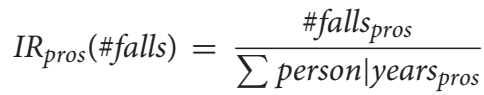

The calculation for the incidence rate ratio (IRR) for fall incidence is below.

$$
I R R(\text { falls })=\frac{I R_{\text {pros }}(\# \text { falls })}{I R_{\text {retro }}(\# \text { falls })}
$$

The IRR confidence intervals were calculated as a two-tailed 95\% limit, using the normalized number of prospective falls

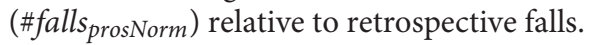

$$
\begin{aligned}
& \# \text { falls }_{\text {prosNorm }}=\# \text { falls }_{\text {pros }} \cdot \frac{\sum \text { person }_{\text {years }} \text { retro }}{\sum \text { person } \mid \text { years }} \\
& 95 \% \text { CI limit for IRR(falls })=e^{\left(\ln (I R R) \pm 1.96 \sqrt{\frac{1}{\text { \#falls }_{\text {retro }}+\frac{1}{\# \text { falls prosNorm }}}}\right)}
\end{aligned}
$$

The same calculations were repeated for the number of individuals who fell.

$$
\begin{aligned}
& \text { \#fallers }_{\text {retro }}=\text { number of participants with retrospective fall events } \\
& \text { \#fallers } \text { pros }=\text { number of participants with prospective fall events }
\end{aligned}
$$

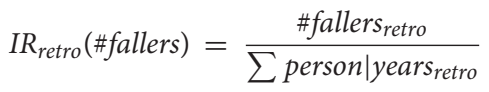

$$
\begin{aligned}
& I R_{\text {pros }}(\# \text { fallers })=\frac{\# \text { fallers pros }}{\sum \text { person } \mid \text { years }}
\end{aligned}
$$


TABLE 1 | Demographics (mean \pm SD) and fall events of the participants tracked, stratified by location.

\begin{tabular}{|c|c|c|c|c|c|c|c|c|c|}
\hline & \multicolumn{3}{|c|}{ All sites } & \multicolumn{3}{|c|}{ Senior living facility (SLF) } & \multicolumn{3}{|c|}{ Senior community center (SCC) } \\
\hline & Female & Male & Total & Female & Male & Total & Female & Male & Total \\
\hline$N$ & 43 & 10 & 53 & 25 & 5 & 30 & 18 & 5 & 23 \\
\hline Age, yrs. & $\begin{array}{c}80.1 \\
( \pm 9.4)\end{array}$ & $\begin{array}{c}81.5 \\
( \pm 7.3)\end{array}$ & $\begin{array}{c}80.4 \\
( \pm 10.2)\end{array}$ & $\begin{array}{c}87.5 \\
( \pm 5.0)\end{array}$ & $\begin{array}{c}82.8 \\
( \pm 8.3)\end{array}$ & $\begin{array}{c}86.7 \\
( \pm 6.0)\end{array}$ & $\begin{array}{c}69.8 \\
( \pm 5.9)\end{array}$ & $\begin{array}{c}80.1 \\
( \pm 7.4)\end{array}$ & $\begin{array}{c}72.1 \\
( \pm 4.8)\end{array}$ \\
\hline $\begin{array}{l}\# \text { falls } S_{\text {retro }} \\
(6 \mathrm{~m})\end{array}$ & 16 & 2 & 18 & 11 & 2 & 13 & 5 & 0 & 5 \\
\hline $\begin{array}{l}\# \text { falls } \text { retro } \\
(12 \mathrm{~m})\end{array}$ & 30 & 7 & 37 & 24 & 7 & 31 & 6 & 0 & 6 \\
\hline $\begin{array}{l}\# \text { \#fallers } \text { retro } \\
(6 \mathrm{~m})\end{array}$ & 13 & 1 & 14 & 9 & 1 & 10 & 4 & 0 & 4 \\
\hline $\begin{array}{l}\# \text { \#allers } \text { retro } \\
(12 \mathrm{~m})\end{array}$ & 18 & 3 & 21 & 13 & 3 & 16 & 5 & 0 & 5 \\
\hline $\begin{array}{l}{ }^{\dagger} \text { \#falls/ } \\
\text { \#fallerspros }\end{array}$ & 7 & 0 & 7 & 4 & 1 & 5 & 2 & 0 & 2 \\
\hline $\begin{array}{l}\text { Length tracked, } \\
\text { yrs. }\end{array}$ & $\begin{array}{c}0.73 \\
( \pm 0.7)\end{array}$ & $\begin{array}{c}0.71 \\
( \pm 0.6)\end{array}$ & $\begin{array}{c}0.73 \\
( \pm 0.6)\end{array}$ & $\begin{array}{c}1.00 \\
( \pm 0.7)\end{array}$ & $\begin{array}{c}0.88 \\
( \pm 0.7)\end{array}$ & $\begin{array}{c}0.98 \\
( \pm 0.8)\end{array}$ & $\begin{array}{c}0.36 \\
( \pm 0.3)\end{array}$ & $\begin{array}{c}0.55 \\
( \pm 0.5)\end{array}$ & $\begin{array}{c}0.4 \\
( \pm 0.3)\end{array}$ \\
\hline
\end{tabular}

${ }^{\dagger}$ Denotes the number of falls observed and the number of fallers observed prospectively was equal as no participant fell more than once during the period of enrollment.

The calculation for the incidence rate ratio (IRR) for incidence of fallers is below.

$$
\operatorname{IRR}(\# \text { fallers })=\frac{I R_{\text {pros }}(\# \text { fallers })}{I R_{\text {retro }}(\# \text { fallers })}
$$

The IRR confidence interval was calculated for a two-tailed 95\% limit, using a normalized number of prospective falls

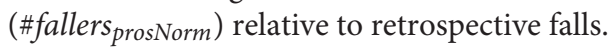

$$
\# \text { fallers }_{\text {prosNorm }}=\text { fallers }_{\text {pros }} \cdot \frac{\sum \text { person } \mid \text { years }}{\text { retro }}
$$

$95 \%$ CI limit for IRR $=e^{\left(\ln (I R R) \pm 1.96 \sqrt{\frac{1}{\# \text { fallers } \text { retro }_{\text {r }}}+\frac{1}{\# \text { fallersprosNorm }}}\right)}$

To estimate the reduction of fall events and reduction in the number of fallers observed in this population after awareness of balance performance made available, retrospective fall history was compared with the normalized prospective fall results to produce a percent reduction:

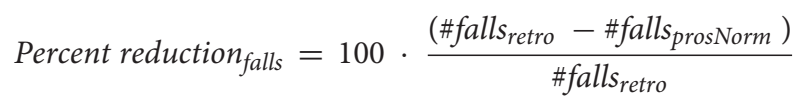

$$
\begin{aligned}
& \text { Percent reduction }_{\text {fallers }}=100 \cdot \frac{\left(\# \text { fallers }_{\text {retro }}-\# \text { fallers }_{\text {prosNorm }}\right)}{\# \text { fallers }}
\end{aligned}
$$

For assessing changes to risk category, the baseline score was defined as the balance score obtained during the initial assessment. A fall risk shift was defined as a change in risk categorization from baseline risk to the risk category associated with the median score of all subsequent scores.

\section{RESULTS}

The total, 53 person-years for the retrospective fall history was collected in this study. The total number of person-years for the prospective fall data was 38.61, as not all participants were tracked for a full year. The SCC participants had shorter tracked periods as they only had three opportunities for testing. The SLF participants, on the other hand, tested themselves 22.3 times on average (ranging from 3 to 107 self-initiated measurements). $96.6 \%$ of all SLF participants tested themselves monthly, of which $75.9 \%$ tested weekly, biweekly or triweekly. The remaining SLF participants tested at a frequency of 2-3 months. During the prospective observation, no participant fell more than once, therefore \#falls pros and \#fallers are numerically equivalent. Table 1 provides demographics and fall events for all included participants stratified by location.

The IR and IRR for the number of falls events and the number of people who fell are listed in Table 2. The true rate ratio lies between 0.13 and 0.53 (all fall events), and 0.21 and 0.98 (number of people who fell), with 95\% confidence. These results indicate a reduction in both the total number of fall events and the number of people who fell while self-monitoring their postural stability. The reduction corresponded to a $74.0 \%$ reduction in falls and a $54.3 \%$ reduction in the number of people who fell after normalizing the rate of prospective falls to the total number of person-years tracked. The trend of reduced falls was further demonstrated with participants who had actual monitored time equaling the retrospective fall history period, Table 3. The reductions in these subsets of the sample ranged from 16.7 to $44.4 \%$.

$42.9 \%$ of participants who were initially categorized as "high risk" (scoring 1-3 during their first postural stability test) "shifted" to a lower risk category (entered "moderate" or "low" risk categories), with a median time of 34 days, while participating in this study. Those who shifted participated twice as long as those who remained high risk (participation of those who remained high risk: $209 \pm 49.7$ days vs. 
individuals who "shifted": $441.6 \pm 99$ days). $23.5 \%$ of those who remained high risk experienced a fall event and accounted for $57.1 \%$ of all prospective falls observed. In contrast, only $8.3 \%$ of those who shifted from a higher to lower risk category experienced a fall. The same fall rate (8.3\%) was observed among those who identified as moderate risk at baseline and remained moderate risk throughout the study.

\section{DISCUSSION}

This study is the first to provide aging adults in both independent living facilities and senior community centers access to a self-initiated and self-monitored postural stability measurement, empowering them to take an active role in the monitoring of their balance health. During this study, it was observed that both the number of people who fell and the total number of falls reported were significantly reduced when participants used the self-monitoring scale and received a "balance score" and an estimate of fall risk.

Typically, multifactorial intervention programs are recommended for fall prevention due to the complex nature of falls (Dionyssiotis, 2012). Yet, in the present study no traditional interventions were provided. We attribute the reducing effect on falls to a possible change in health behaviors. If self-monitoring provides an empowering effect through self-efficacy and self-regulation (Bandura, 1991; Lee et al., 2007, 2008; Michie et al., 2009), an objective, quantified measure of fall risk and "balance" could reasonably influence the

TABLE 2 | Incidence rate (IR) and incidence rate ratio (IRR) results for number of falls and number of people who fell during retrospective analyses and prospective observation.

\begin{tabular}{lc}
\hline Fall events (falls) & \\
$I_{\text {retro }}$ (falls) & 0.698 \\
$I_{\text {pros }}$ (falls) & 0.181 \\
$I R R[95 \% \mathrm{Cl}]$ & $0.260[0.128-0.528]^{*}$ \\
Number of fallers (fallers) & 0.396 \\
$I_{\text {retro }}$ (fallers) & 0.181 \\
$I_{\text {pros }}($ fallers) & $0.438[0.213-0.982]^{*}$ \\
$I R R[95 \% \mathrm{Cl}]$
\end{tabular}

*Indicates statistical significance at $p<0.05$ (95\% confidence interval of IRR excludes null value). health behaviors of people aiming to reduce their fall risk individuals with a history of falling and concern for future fall related injuries.

The greatest reductions in falls were seen in the participants who shifted from high risk at baseline to moderate risk. This "shifting" group indirectly demonstrated increased self-efficacy as they voluntarily measured themselves 232 days longer, on average, than those who remained scoring in the high risk category. It is possible that those selfmonitoring for longer were increasing self-efficacy in exercise behaviors, also. By shifting risk category, this group also received positive reinforcement from an improving score, which in and of itself could have been the motivator for continued self-monitoring and behavioral change. Regardless of the cause, the participant's awareness of their fall risk and postural stability state, through knowledge of their "balance score," may have elicited a change in their health behaviors, which in turn reduced their fall rates, however future studies will be required to determine the nature of this relationship.

Increased exercise, safety measures and "carefulness" are the most likely behavioral changes that would have occurred as they are the easiest for the individual to modulate without clinical assistance. Indeed, exercise alone has demonstrated a protective effect, reducing incidences of falls (Shumway-Cook et al., 1997; Taggart, 2002; Grabiner et al., 2012; Halvarsson et al., 2015; Shier et al., 2016; Sherrington et al., 2017). Changing exercise health behaviors in older adults could be effective as the majority of older adults do insufficient exercise for health benefits (Ashe et al., 2009; Schoenborn et al., 2013). The barriers to initiating and adhering to exercise for many older adults are psychological and attitudinal (Lee et al., 2008). Fortunately, self-monitoring and self-efficacy approaches in exercise interventions have enabled people to overcome these psychological barriers (Lee et al., 2008; Michie et al., 2009) and change health behaviors (Lee et al., 2007, 2008; Michie et al., 2009; Wang et al., 2016; Maher et al., 2017; Sullivan and Lachman, 2017).

In the current study, the effect of self-monitoring may have been further strengthened as the "balance score" provided physiological feedback about the individual's postural stability and balance control-factors which an individual may intuit are related to their risk of falling. This physiological information is not normally accessible with consumer technology thereby providing novel insights into health status in contrast to behavioral measures which are more typically available, such

TABLE 3 | Comparison of number of falls and fallers data for participants with 6 and 12 months of actual fall tracking data with their equivalent fall history.

\begin{tabular}{|c|c|c|c|c|c|c|c|c|}
\hline Time & $N$ & $\begin{array}{l}\text { Age, } \\
\text { yrs. }\end{array}$ & \#falls retro & \#fallspros & $\%$ reduction & \#fallers $S_{\text {retro }}$ & \#fallerspros & $\%$ reduction \\
\hline 6 months & 21 & $\begin{array}{c}85.5 \\
( \pm 6.9)\end{array}$ & 7 & 5 & $28.6 \%$ & 6 & 5 & $16.7 \%$ \\
\hline 12 months & 13 & $\begin{array}{c}83.8 \\
( \pm 5.8)\end{array}$ & 9 & 6 & $44.4 \%$ & 6 & 5 & $16.7 \%$ \\
\hline
\end{tabular}


as the number of steps taken in a day. Evidence from a recent fMRI study demonstrated a greater level of brain activation with physiological self-monitoring via blood glucose testing over behavioral self-monitoring through step count estimations, which corresponded with improvements in physical activity health behavior (Whelan et al., 2017a,b). Taken together, it is possible that providing physiological feedback that is less intuitive or less readily observable results in greater health behavior modification. However, any possible impact on an individual's fear of falling may vary based on their fall risk status. Further investigation is necessary to understand the relationship between fear of falling and selfmonitoring balance.

Self-monitoring with this physiological feedback may also impact an additional psychological component that is unique to fall prevention: fear of falling. Fear of falling is present in $21-85 \%$ of older adults, fallers and non-fallers alike, and is associated with decreased physical activity, depression, less social contact, avoidance of activities, and increased fall risk (Scheffer et al., 2008). While fear is linked with potential future fall events, the anxiety created by the uncertainty of the individual's risk and likelihood of a fall event is highly noxious (Grupe and Nitschke, 2013). Self-monitoring may also reduce this anxiety by replacing the uncertainty with information about the person's physiological state of stability and fall risk.

We propose that the empowering effect of self-monitoring fall risk and instability could have been especially potent because older adults may have been educated on the benefits of exercise and fall prevention, but they often have limited knowledge and understanding about their own fall risk/balance state. Consequently, the sudden awareness in this domain may have the potential for greater potency than for exercise measures alone, where general knowledge of one's state is greater.

The limitations of this study were related to sources of potential bias in the sample. Serial fallers, individuals who experience recurring falls with minimal injury, have the potential to skew fall rates in aging populations. By comparing the number of fallers in addition to the total number of falls observed, the inflating bias of serial fallers upon the total number of falls is limited and helps to provide confidence in a generalizable interpretation of the results. The sample may also have bias due to the smaller sample and strong gender bias. The gender bias is difficult to avoid due to the gender ratio of females to males in this age group. Females are generally more receptive and proactive about preventive health (Center for Disease Control Prevention, 2001), so may have been more likely to voluntarily participate and seek to change their health behaviors. However, despite the small numbers, a reduction in the number of falls within the male population was observed.

To address potential bias of the small sample, we recruited from two different types of locations. The independent living facility included on-site residential living, while the senior community center was only accessible during daytime hours. Consequently, the length of participant follow-up for the purposes of fall tracking was variable, further compounded by participant availability and dropout due to loss of life. Furthermore, the increased follow-up with individuals in the independent living facilities (monthly) may have encouraged greater participation than those in the community (follow-up every 3 months). To explore the influence of variable follow-up lengths, an assessment of a smaller subset of participants who had actual tracked months equal to the fall history durations was performed at 6 and 12 months of tracking. Again, the reduced trend in the actual number of falls and the number of fallers was observed at both the 6 and 12 months periods. Across both locations there was a variety of participant lifestyles ranging from single to cohabitation, limited to extensive activity, and international travel to a local daily existence. There was also a significant imbalance between male and female participants at each of the sites, however this is consistent with expectations of heterogenous populations among older adults (Lowsky et al., 2014). Finally, self-reporting of falls may have introduced measurement error as fall events are well-known to be under reported with increasing recall time (Mackenzie et al., 2006). In this study, the longest recall period for remembering fall events was 2 months prospectively and 12 months retrospectively. As a result, it is expected that retrospective fall rates are underreported in this sample, which would have the consequence of limiting the effect of self-monitoring of balance upon the number of reported falls and fallers.

A final limitation of this study is the fact that participants self-selected the cadence and duration of their participation, as well as self-selected their responses to the balance scores they received. Although this study lacked controlled exploration of factors which may influence balance health, postural stability, and fall risk, we propose that is provides a real-world preliminary evaluation of the impact of objective balance health assessments upon fall risk in a predictably heterogeneous population of older adults (Lowsky et al., 2014).

\section{CONCLUSIONS}

This study suggests that the awareness gained from selfmonitoring of balance and fall risk has a positive effect on fall rates. Empowering self-assessment for older adults was also observed to reduce the incidence of falls. Although the determination of causal factors associated with this reduction in falls is not addressed in the current study, we expect successful future interventions will leverage self-monitoring of balance as a primary component of care alongside traditional fall-reduction interventions. Future work is needed to further understand the role of gender, and determine if fear of falling, individual self-efficacy, physical activity levels and other health behaviors are altered as a result of self-monitored physiological feedback related to postural instability and fall risk.

\section{DATA AVAILABILITY STATEMENT}

The raw data supporting the conclusions of this article will be made available by the authors, without undue reservation. 


\section{ETHICS STATEMENT}

The studies involving human participants were reviewed and approved by University of Houston Institutional Review Board (IRB). The patients/participants provided their written informed consent to participate in this study.

\section{AUTHOR CONTRIBUTIONS}

KF and SM developed the theoretical framework for the study and CL provided guidance to limit conflict of interest. SM developed the experimental framework. KF performed data collection and synthesized results. KF, CL, and SM participated in data interpretation and preparation of the manuscript.

\section{REFERENCES}

Ashe, M. C., Miller, W. C., Eng, J. J., Noreau, L., Physical Activity and Chronic Conditions Research Team (2009). Older adults, chronic disease and leisuretime physical activity. Gerontology 55, 64-72. doi: 10.1159/000141518

Bandura, A. (1991). Social cognitive theory of self-regulation. Organ. Behav. Hum. Decis. Process. 50, 248-287. doi: 10.1016/0749-5978(91)90022-L

Center for Disease Control and Prevention (2001). Utilization of Ambulatory Medical Care by Women: United States, 1997-98. Data from the National Health Care Survey. Vital and Health Statistics, 13.

Dionyssiotis, Y. (2012). Analyzing the problem of falls among older people. Int. J. Gen. Med. 5, 805-813. doi: 10.2147/IJGM.S32651

Florence, C. S., Bergen, G., Atherly, A., Burns, E., Stevens, J., and Drake, C. (2018). Medical costs of fatal and nonfatal falls in older adults. J. Am. Geriatr. Soc. 66, 693-698. doi: 10.1111/jgs.15304

Forth, K., and Lieberman Aiden, E. (2019). Identifying fall risk using machine learning algorithms. U.S. Patent No 0,269,354. Washington, DC: U.S. Patent and Trademark Office.

Forth, K. E., Wirfel, K. L., Adams, S. D., Rianon, N. J., Lieberman-Aiden, E., and Madansingh, S. I. (2020). A postural assessment utilizing machine learning prospectively identifies older adults at a high risk of falling. Front. Med. 7:926. doi: 10.3389/fmed.2020.591517

Ganz, D. A., Bao, Y., Shekelle, P. G., and Rubenstein, L. Z. (2007). Will my patient fall? JAMA 297, 77-86. doi: 10.1001/jama.297.1.77

Gillespie, L. D., Robertson, M. C., Gillespie, W. J., Sherrington, C., Gates, S., Clemson, L. M., et al. (2012). Interventions for preventing falls in older people living in the community. Cochr. Datab. Syst. Rev. 9:CD007146. doi: 10.1002/14651858.CD007146.pub3

Grabiner, M. D., Bareither, M. L., Gatts, S., Marone, J., and Troy, K. L. (2012). Taskspecific training reduces trip-related fall risk in women. Med. Sci. Sports Exerc. 44, 2410-2414. doi: 10.1249/MSS.0b013e318268c89f

Grupe, D. W., and Nitschke, J. B. (2013). Uncertainty and anticipation in anxiety. Nat. Rev. Neurosci. 14, 488-501. doi: 10.1038/nrn3524

Halvarsson, A., Franzén, E., and Ståhle, A. (2015). Balance training with multitask exercises improves fall-related self-efficacy, gait, balance performance and physical function in older adults with osteoporosis: a randomized controlled trial. Clin. Rehabil. 29, 365-375. doi: 10.1177/0269215514544983

Hannan, M. T., Gagnon, M. M., Aneja, J., Jones, R. N., Cupples, L. A., Lipsitz, L. A., et al. (2010). Optimizing the tracking of falls in studies of older participants: comparison of quarterly telephone recall with monthly falls calendars in the MOBILIZE Boston study. Am. J. Epidemiol. 171, 1031-1036. doi: 10.1093/aje/kwq024

Joutsijoki, H., Rasku, J., Pyykkö I., and Juhola, M. (2019). Classification of patients and controls based on stabilogram signal data. Intell. Data Anal. 23, 215-226. doi: 10.3233/IDA-173704

Lee, L.-L., Arthur, A., and Avis, M. (2008). Using self-efficacy theory to develop interventions that help older people overcome psychological barriers to
All authors contributed to the article and approved the submitted version.

\section{FUNDING}

Zibrio Inc., a privately held company, provided financial support for this study.

\section{ACKNOWLEDGMENTS}

The authors wish to thank Heather Prigmore and Angela Robertson for their contributions during data collection with both the community dwelling and independent living older adults. physical activity: a discussion paper. Int. J. Nurs. Stud. 45, 1690-1699. doi: 10.1016/j.ijnurstu.2008.02.012

Lee, L.-L., Avis, M., and Arthur, A. (2007). The role of self-efficacy in older people's decisions to initiate and maintain regular walking as exercise - Findings from a qualitative study. Prev. Med. 45, 62-65. doi: 10.1016/j.ypmed.2007. 04.011

Lord, S. R., and Dayhew, J. (2001). Visual risk factors for falls in older people. J. Am. Geriatr. Soc. 49, 508-515. doi: 10.1046/j.1532-5415.2001.49107.x

Lowsky, D. J., Olshansky, S. J., Bhattacharya, J., and Goldman, D. P. (2014). Heterogeneity in Healthy Aging. J. Gerontol. A Biol. Sci. Med. Sci. 69, 640-649. doi: $10.1093 /$ gerona/glt162

Mackenzie, L., Byles, J., and D'Este, C. (2006). Validation of selfreported fall events in intervention studies. Clin. Rehabil. 20, 331-339. doi: 10.1191/0269215506cr947oa

Maher, C., Ryan, J., Ambrosi, C., and Edney, S. (2017). Users' experiences of wearable activity trackers: a cross-sectional study. BMC Public Health 17:880. doi: 10.1186/s12889-017-4888-1

Michie, S., Abraham, C., Whittington, C., McAteer, J., and Gupta, S. (2009). Effective techniques in healthy eating and physical activity interventions: a meta-regression. Health Psychol. Off. J. Div. Health Psychol. Am. Psychol. Assoc. 28, 690-701. doi: 10.1037/a0016136

Rasku, J., Juhola, M., Tossavainen, T., Pyykko, I., and Toppila, E. (2008). Modelling stabilograms with hidden Markov models. J. Med. Eng. Technol. 32, 273-283. doi: 10.1080/03091900600968908

Rubenstein, L. Z. (2006). Falls in older people: epidemiology, risk factors and strategies for prevention. Age Ageing 35, ii37-ii41. doi: 10.1093/ageing/ afl084

Scheffer, A. C., Schuurmans, M. J., Dijk, N., van Hooft, T., and van der Rooij, S. E. de. (2008). Fear of falling: measurement strategy, prevalence, risk factors and consequences among older persons. Age Ageing 37, 19-24. doi: 10.1093/ageing/afm169

Schoenborn, C. A., Adams, P. F., and Peregoy, J. A. (2013). Health behaviors of adults: United States, 2008-2010. Vital Health Stat. 10 257, 1-184.

Sherrington, C., Michaleff, Z. A., Fairhall, N., Paul, S. S., Tiedemann, A., Whitney, J., et al. (2017). Exercise to prevent falls in older adults: an updated systematic review and meta-analysis. Br. J. Sports Med. 51, 1750-1758. doi: 10.1136/bjsports-2016-096547

Shier, V., Trieu, E., and Ganz, D. A. (2016). Implementing exercise programs to prevent falls: systematic descriptive review. Inj Epidemiol. 3:16. doi: 10.1186/s40621-016-0081-8

Shumway-Cook, A., Gruber, W., Baldwin, M., and Liao, S. (1997). The effect of multidimensional exercises on balance, mobility, and fall risk in communitydwelling older adults. Phys. Ther. 77, 46-57. doi: 10.1093/ptj/77.1.46

Sullivan, A. N., and Lachman, M. E. (2017). Behavior change with fitness technology in sedentary adults: a review of the evidence for increasing physical activity. Front. Pub. Health 4:289. doi: 10.3389/fpubh.2016. 00289 
Taggart, H. M. (2002). Effects of Tai Chi exercise on balance, functional mobility, and fear of falling among older women. Appl. Nurs. Res. 15, 235-242. doi: 10.1053/apnr.2002.35975

Tinetti, M. E., Speechley, M., and Ginter, S. F. (1988). Risk factors for falls among elderly persons living in the community. N. Engl. J. Med. 319, 1701-1707. doi: 10.1056/NEJM198812293192604

Wang, J. B., Cataldo, J. K., Ayala, G. X., Natarajan, L., Cadmus-Bertram, L. A., White, M. M., et al. (2016). Mobile and wearable device features that matter in promoting physical activity. J. Mob. Technol. Med. 5, 2-11. doi: $10.7309 /$ jmtm.5.2.2

Whelan, M. E., Morgan, P. S., Sherar, L. B., Kingsnorth, A. P., Magistro, D., and Esliger, D. W. (2017a). Brain activation in response to personalized behavioral and physiological feedback from self-monitoring technology: pilot study. J. Med. Internet Res. 19:e384. doi: 10.2196/jmir.8890

Whelan, M. E., Morgan, P. S., Sherar, L. B., Kingsnorth, A. P., Magistro, D., and Esliger, D. W. (2017b). Metadata correction: brain activation in response to personalized behavioral and physiological feedback from self-monitoring technology: pilot study. J. Med. Internet Res. 19:e430. doi: 10.2196/jmir.9426

Young, T. K. (2005). Population Health: Concepts and Methods. New York, NY: Oxford University Press.

Young, W. R., and Mark Williams, A. (2015). How fear of falling can increase fall-risk in older adults: applying psychological theory to practical observations. Gait Posture 41, 7-12. doi: 10.1016/j.gaitpost.2014. 09.006

Conflict of Interest: Zibrio Inc. employs the KF and SM representing a potential for conflict of interest. CL from the University of Houston received no funding support for this study and provided guidance throughout to minimize these conflicts.

Publisher's Note: All claims expressed in this article are solely those of the authors and do not necessarily represent those of their affiliated organizations, or those of the publisher, the editors and the reviewers. Any product that may be evaluated in this article, or claim that may be made by its manufacturer, is not guaranteed or endorsed by the publisher.

Copyright (c) 2021 Forth, Layne and Madansingh. This is an open-access article distributed under the terms of the Creative Commons Attribution License (CC BY). The use, distribution or reproduction in other forums is permitted, provided the original author(s) and the copyright owner(s) are credited and that the original publication in this journal is cited, in accordance with accepted academic practice. No use, distribution or reproduction is permitted which does not comply with these terms. 